\title{
Oasis evolution in response to human induced water resources reallocation in South Xinjiang during past four decades
}

\author{
Yuanxu Ma*, Jianping Wang, Fang Yan, Aynur Mamat \\ Key Laboratory of Digital Earth Science, Institute of Remote Sensing and Digital Earth, Chinese Academy of \\ Sciences, Beijing 10094 China \\ * Corresponding author: mayx@radi.ac.cn
}

\begin{abstract}
Vegetation in drylands is sensitive to climatic changes and human activities. Remote sensing and spatial analyses provide us useful tools for monitoring long-term vegetation dynamics over large regional scale. In this study, we analyzed the oasis vegetation cover change of the Tarim Basin using Landsat data sets from six epochs, 1975s, 1990s, 2000s, 2005s, 2010s and 2014. The results show that vegetation cover of oases increases from $34600 \mathrm{~km}^{2}$ in $1975 \mathrm{~s}$ to $101000 \mathrm{~km}^{2}$ in 2014, though there was a vegetation coverage decrease from $77600 \mathrm{~km}^{2}$ in $2000 \mathrm{~s}$ to $42680 \mathrm{~km}^{2}$ in $2010 \mathrm{~s}$. The percentage of annul water consumption has increased from $34 \%$ in 1970 s to $52 \%$ in 2010 s in the upper Tarim River, and decreased from 15\% in 1970s to $9 \%$ in 2010s in the lower Tarim River. The decrease of oases area from 2000s to 2010s probably resulted from the rapid urbanization and large scale land reclamation. Although there is an increasing trend for oases coverage, local degradation of oases especially in the northern part occurred. This may be caused by inadequate water supply of the Tarim River. The results of multiple regression show that human activities contribute $70 \%$ of oases area change. Human induced water resources reallocation and heat energy balance is the primary cause of total oasis change.

Keywords: Oasis; Climatic change; Human activities; Water resources; Remote Sensing; Tarim River basin
\end{abstract}

\section{Introduction}

Dryland is characterized by high climate variability (low precipitation, long dry seasons, high wind speed, and frequent dust storms), and are quite sensitive to land use practice [1,2]. Drylands totally cover about $40 \%$ of terrestrial land surface and occupy $38 \%$ of living places of the global population [1-3]. Drylands can account for approximately $40 \%$ of global net primary productivity $[2,4,5]$, which made nearly equal proportion compared with the other land types. With rapid population growth, intensive human activities have resulted in land degradation and desertification [2], which bring great challenge to environmental sustainability in drylands.

Oasis represent a unique ecosystem in arid and semi-arid regions [6-9]. An oasis is ecologically defined as an ecosystem that has higher vegetation cover and primary productivity than surrounding desert and significantly depends on external water supply [9]. The origination and evolution of oases are significantly dependent on specific hydrologic, topographic and geologic settings [10,11]. A systematic mapping from remote sensing data shows that oases are geographically distributed on alluvial fans and along the rivers channels [12]. Precipitation is an important input of water sources to oases, however snow and glacier melting water from surrounding high mountains provide a more significant source. The oases naturally oppose the encroachment of desert by staying moist in the soil $[8,11]$. Some investigations have attempted to manifest how to maintain sustainable development of oases by controlling the local circulation of hydrothermal environment [13,14]. In the context of global change and human modification, large-scale hydrological cycling and spatial configuration of water resources has been changed substantially $[7,15]$, which potentially affect the development and 
self-regulation of oases [6,8].

The condition of vegetation growth and cover plays an important role in terrestrial ecosystem and hydrological cycle, especially in drylands with limited water input $[1,16]$. Although filed investigation could provide more accurate information about vegetation condition, it's laborious and time-consuming. The integrations of approaches from remote sensing, spatial statistics, and geoinformatics provide powerful tools to monitor large scale vegetation encroachment and desertification in drylands over multiple decades [1]. The consistency and repeatability of satellite data allow to compare the regional change through image-to-image measurement at the same thematic scale [17]. All various spectral vegetation indices, the Normalized Difference Vegetation Index (NDVI) is the most widely used one [18], which serves as a good indicator of vegetation productivity [19]. On this basis, NDVI can be employed to the long-term monitoring of oases dynamics.

In china, oases are mainly distributed along the pediments of surrounding mountains in northwestern dryland regions [20,21]. In these regions oases account for only about $5 \%$ of the total land surface area, but feed more than $90 \%$ the local growing population and social wealth $[8,13,14,22]$. It has been observed that desertification is happening and causes the environmental deterioration of oases [23,24] because of unsustainable economic development [25]. Large part of South Xinjiang has an arid climate, and is prone to change as a result of highly variable climate and intensifying human activities. As the primary living places of dryland population, oases are theoretically and practically fundamental to the social and economic developments in this region. Long-term monitoring is essential to our explicit understanding of the oases dynamic. Hence, the objective of this study is to map the spatial and temporal changes of oases vegetation using long time series of remote sensing datasets and identify the major factors affecting oases change.

\section{Study Area}

The study area is located in the Tarim Basin in South Xinjiang, which includes five sub-provisional prefectures (Figure 1). The Tarim Basin is enclosed by Tien Shan to the North, the Pamir Plateau to the West, and the Kunlun Mountain to the South. In the central part of the basin is the Taklimakan Desert, which covers $85 \%$ of the whole basin (Sun and Liu, 2006). The Tarim River originates from the Pamir Plateau and then fed by a series of rivers from the surrounding high mountains flowing from the southern-southwestern part to the northeastern part of the basin (Figure 1). The total catchment area is about $1.02 \times 10^{6} \mathrm{~km}^{2}$ [26]. Historically, nine headwater drainage systems were hydrologically connected to the main stream of the Tarim River, however, currently only three major headwaters (the Aksu River, Yarkant River, and Hotan River) flow into the mainstream. The mean annual runoff in the Tarim basin is about $39.8 \mathrm{~km}^{3}, 40 \%$ of which comes from glacial and snowmelt water $[27,28]$. The Aksu River, Hotan River, and Yarkand River contribute 73.2\%, 23.2\% and 3.6\% of the total runoff, respectively [28]. The Tarim River basin covers 42 counties, and 55 Production and Construction Units of Xinjiang. During the last 50 years, the ecosystems and environments of the Tarim River have been changed significantly due to extensive agricultural exploitation in the area [29]. Recent investigations showed that annual runoff in the middle and lower reaches of the Tarim River reduced significantly. It is argued that human activities (irrigation and domestic water use) has led to a decrease of the water into the main stream of the Tarim River Basin since 1970s, which was aggravated in the 2000s [26,30,31]. 


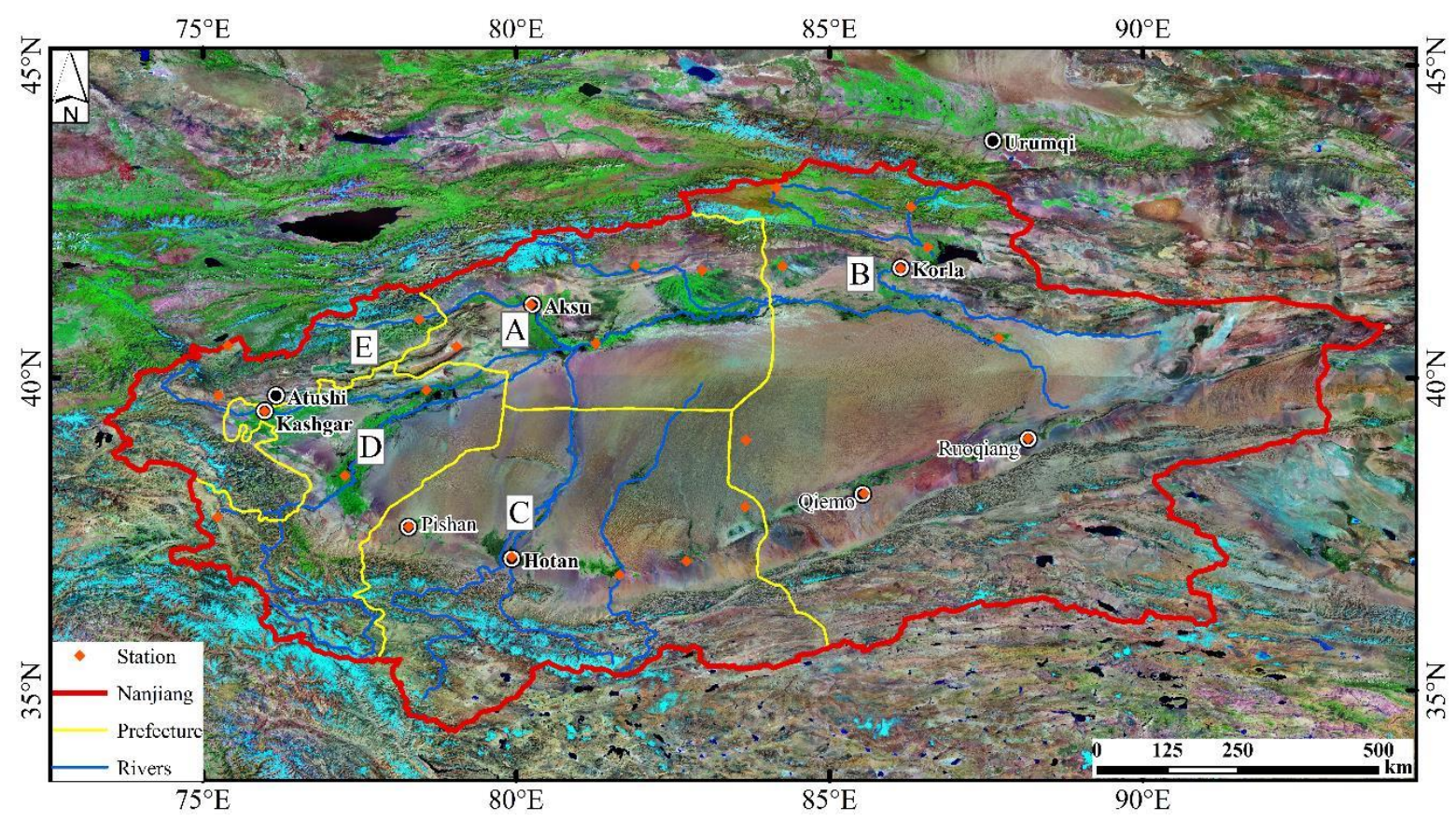

Figure 1. Landsat mosaic image showing location map of the study area and spatial distribution of meteorological stations in South Xinjiang. The five prefectures labeled in figure are: A. Aksu, B. Bayinguole, C. Hotan, D. Kashgar, and E. Kizilsu. In this study five stations (Aksu, Korla, Kashi, Hotan, and Ruoqiang) were selected to show the climate characteristics in different regions.

The climate in the Tarim River catchment is extremely dry with high temperature and low precipitation. The mean annual temperature varies from $10.6{ }^{\circ} \mathrm{C}$ to $11.5^{\circ} \mathrm{C}$, with the mean monthly temperature between $20^{\circ} \mathrm{C}-30^{\circ} \mathrm{C}$ in July and $10^{\circ} \mathrm{C}-20^{\circ} \mathrm{C}$ in January [26]. The mean annual precipitation is about $116.8 \mathrm{~mm}$, but the annual potential evaporation is as high as $2500-3000 \mathrm{~mm}$ [26]. The annual precipitation exhibits an elevation-dependent decreasing gradient, from 200-500 $\mathrm{mm}$ in the mountainous area, to $50-80 \mathrm{~mm}$ in the pediments of the mountain or alluvial fans, and then to less than $10 \mathrm{~mm}$ in desert of the central basin [32]. The interannual distribution of precipitation is significantly heterogeneous. More than $80 \%$ of the total annual precipitation falls within the period from May to October, and less than 20\% falls between November and April [26].

\section{Data and methods}

\subsection{Data}

All datasets used in this study were retrieved from Global Land Cover Facility (GLCF) of Maryland University (http://glcf.umd.edu/) and Geospatial Data Cloud of Chinese Academy (http://www.gscloud.cn/). The Landsat MSS/TM/ETM+ datasets was from the Global Land Survey (GLS) collection, which is designed to meet a need from scientists to use a carefully coordinated collection of high resolution imagery for global modeling, including for the climate and carbon cycles (http://glcf.umd.edu/data/gls/). Based on the existing GeoCover dataset, the GLS provides wall-towall, georeferenced and orthorectified, cloud free Landsat coverage of Earth's land area at 30-meter resolution in nominal "epochs" of 1975s, 1990s, 2000s, 2005s, and 2010s (Franks et al., 2009; Gutman et al., 2008). The GLS is intended to provide clear-view images acquired during the peak growing season of each epoch [17]. However, when high quality images were not available due to lack of cloud-free images during the growing season (Franks et al., 2009; Gutman et al., 2008), images had to be selected with a date outside this range [17]. This may cause certain derivation when change detection during two different periods is performed. The images from 1975s and 1990s are originally 
orthorectified data which was not calibrated by atmospheric correction and transformed into surface reflectance (Tucker et al., 2004). The data from 2000s, 2005s, and 2010s were surface reflectance production after atmospheric correction using Landsat Ecosystem Disturbance Adaptive Processing System (LEDAPS). The datasets for each epoch were acquired from the primary Landsat sensor in use at the time. The image datasets used for the year of 2014 was Landsat 8 OLI_TRIS retrieved from Geospatial Data Cloud of Chinese Academy (http://www.gscloud.cn/). For each epoch, totally 26 scenes of images are chosen to cover the extent of oases in South Xinjiang (Tables S1 and S2).

In addition, SRTM DEM (http://www.gscloud.cn/) was used to extract the contour line for delineating the extent of oases. In this study, the area below $2000 \mathrm{~m}$ above sea level is determined as the habitat place of oases.

Precipitation and temperature datasets from five stations (Figure 1) were used to investigate the relationship between oases changes and climatic variables. The time span of meteorological data used here range from 1971 to 2012.

\subsection{Methods}

Because of the datasets of 1975s, 1990s and 2014 were just georeferenced and orthorectified, they need to be corrected and transformed into surface reflectance before they are used to calculate NDVI. The atmospheric correction method adopted here is FLAASH. The digital number (DN) values of the data were converted into at-satellite radiance, and then the at-satellite radiances were converted to surface reflectance by correcting for both solar and atmospheric effects [33].

NDVI was used to map the spatiotemporal changes of vegetation cover of oases. It was suggested that the value of 0.1 was appropriate to discriminate the vegetation from other land cover types [34]. The values of large than 0.1 was defined as vegetation. It was cross checked through comparison of NDVI results and the atmospherically corrected images. Because the oases are geographically distributed in the places below $2000 \mathrm{~m}$ above sea level, the area below $2000 \mathrm{~m}$ and with NDVI values of large than 0.1 was regarded as oases.

In order to achieve a quantitative understanding of the contribution of climatic changes and human activities to oases area change, we performed a multiple regression analysis. We chose 18 counties with enough data sets from the years 1990, 2000, and 2005 for experimental samples. These 18 counties are distributed in different region of the Tarim basin, which is representative for this analysis (Figure 2). Because of the limited data of water consumption, here population and farmland were considered as the two primary variable accounting for human activities, and annual precipitation and mean annual temperature as the primary variables for climatic changes. The oasis area is considered as independent variable, and the four influencing variables as dependent variables. All the data are normalized before multiple regression, and the derived coefficients of the corresponding variables represent their relative contribution to the variation of oasis. 


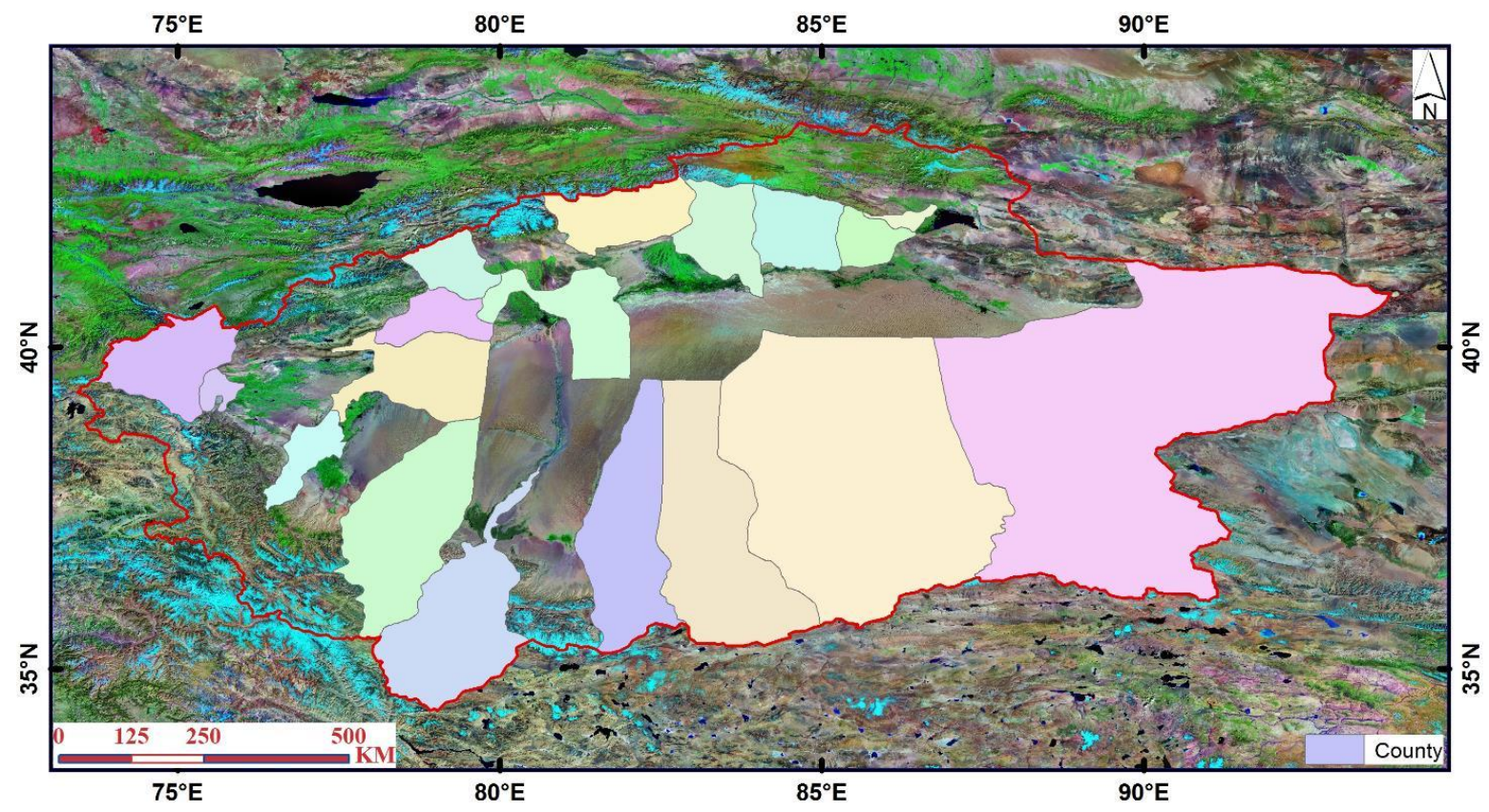

Figure 2. The eighteen counties selected for quantifying the contribution of varying variables to oasis area change using multiple regression.

\section{Results and Discussion}

\subsection{Spatiotemporal changes of oases}

As mentioned in the section of 'method', the spatial patterns of oases were mapped using NDVI with value of large than 0.1 (Figure 3). This value may introduce some error because of the image quality and temporal and spatial differences of surface reflectance (see some sparse patches around the Hotan oases in 1975s). However, the results is still considered to be reliable in that the oases has a significant expansion with the population growth and the cropland increase [6] (Figure 9). The spatial patterns of vegetation cover during different periods are shown in Figures 4 and 5 . And the oases area in the whole region and five sub-provisional prefectures are calculated, respectively (Figure 6). For the whole study region, the vegetation cover in the oases increases from in $34600 \mathrm{~km}^{2}$ in 1975 s to $10100 \mathrm{~km}^{2}$ in 2014, with a decrease from $77600 \mathrm{~km}^{2}$ in $2000 \mathrm{~s}$ to $42680 \mathrm{~km}^{2}$ in 2010 s (Figure 6). There is no significant change between 2005s and 2010s, despite of some sparse increase or decrease within the study area. Except Hotan, the temporal changes of oases area in other four prefecture have the same increasing-decreasing-increasing changing trends with the whole study region. The area of oases in Hotan shows no significant change from 1975s to 2010s. However, from 2010s to 2014, there is an obvious increase.

The results from the comparison between 2014 and 1990s (Figure 5) show that vegetation cover increases in most parts of the headwaters in the upper reach from Aksu and decreases over large spatial scale along the middle and lower reaches of the Tarim River from 1990s to 2014. The construction of reservoirs in the headwaters to great extent accounted for the expansion of oases (Figure 5B), and then the shrinkage of the Tarim River accounted for the degradation of oases in the lower reach (Figure 5C). 

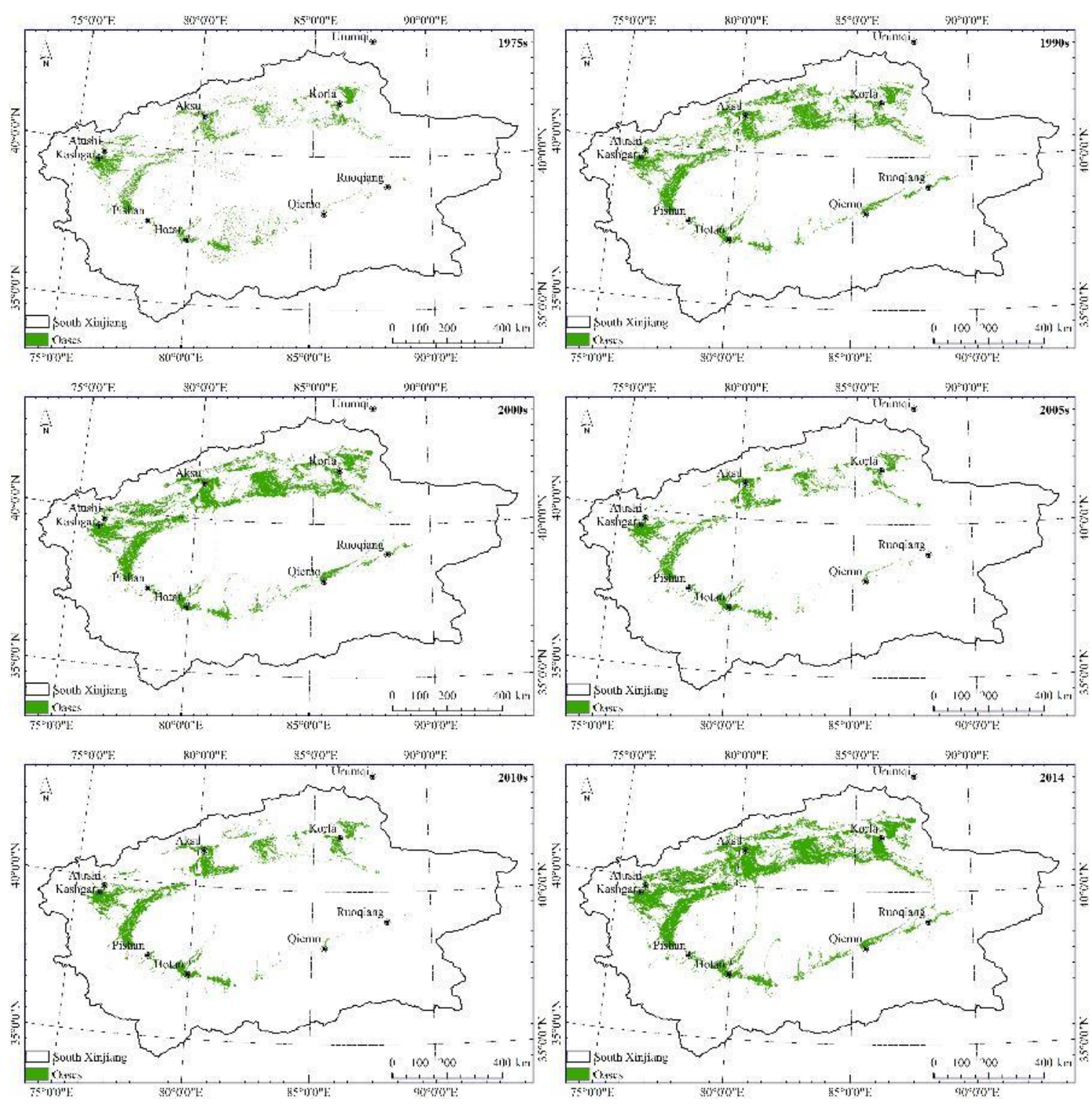

Figure 3. Spatial pattern of oases in South Xinjiang during six different periods.

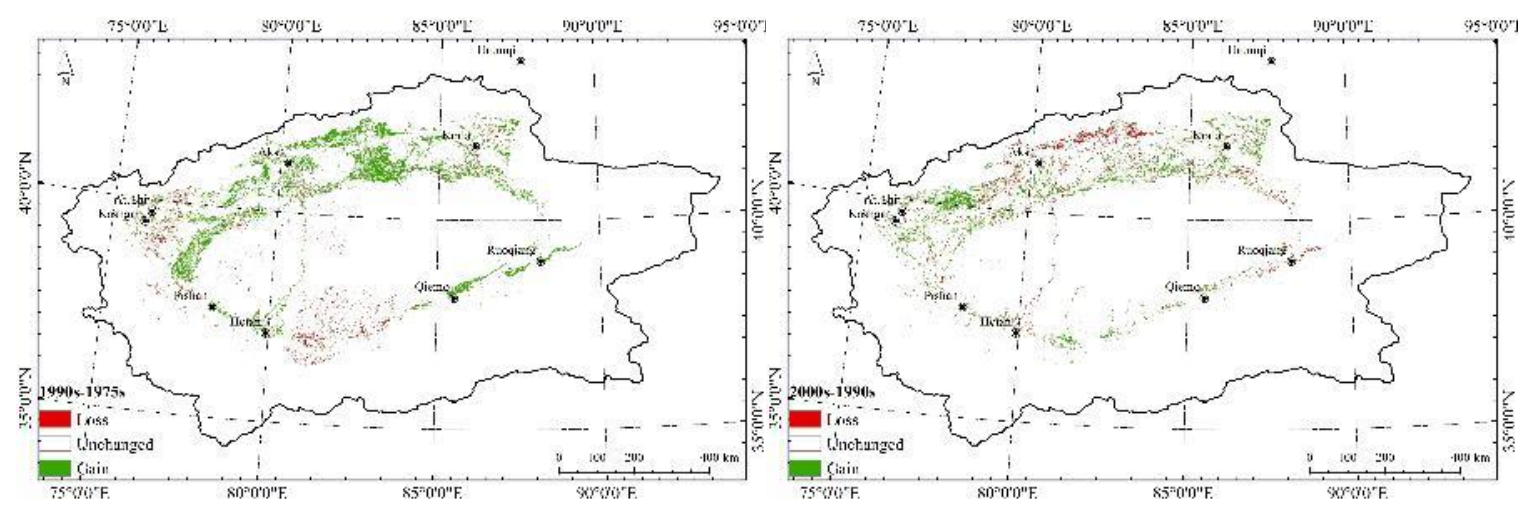



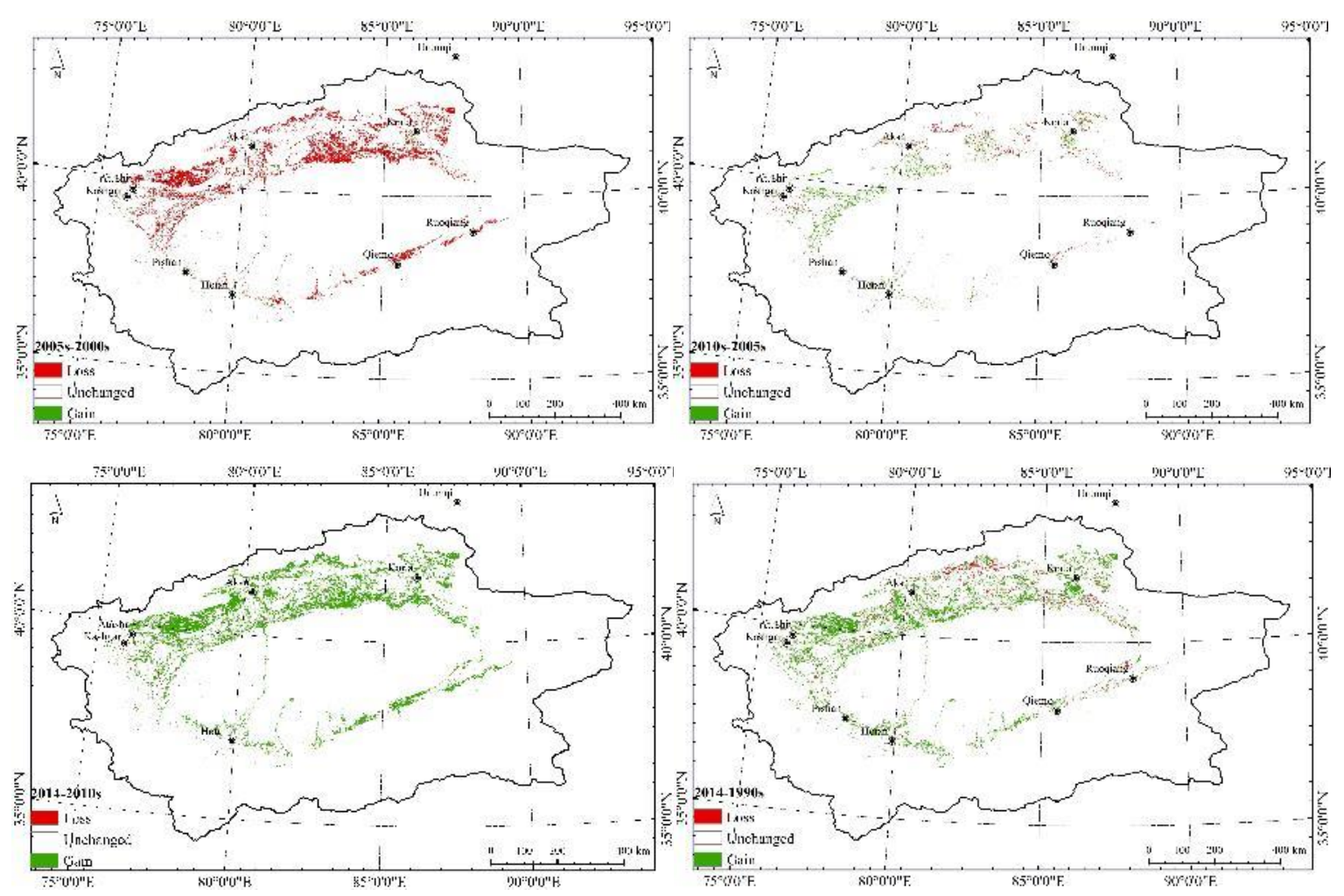

Figure 4. Spatial changes of vegetation cover in oases between different periods. The green area means increasing vegetation cover and red area means decreasing vegetation cover. 


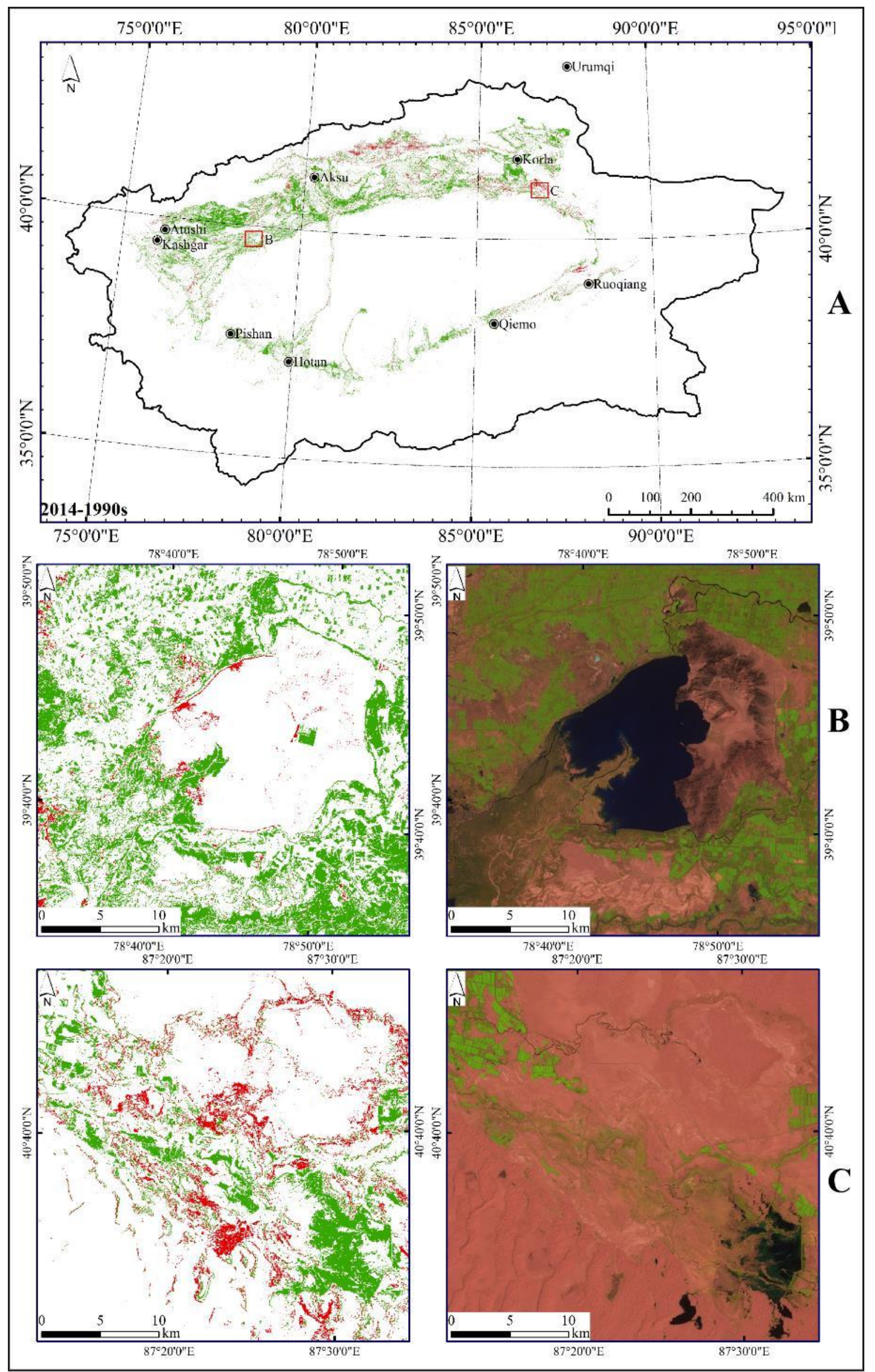


Figure 5. The representative areas are chosen to show the spatiotemporal changes of oases in the Tarim River basin. A. South Xinjiang; B. Xiaohaizi Reservoir surrounding area; C. the lower Tarim River.
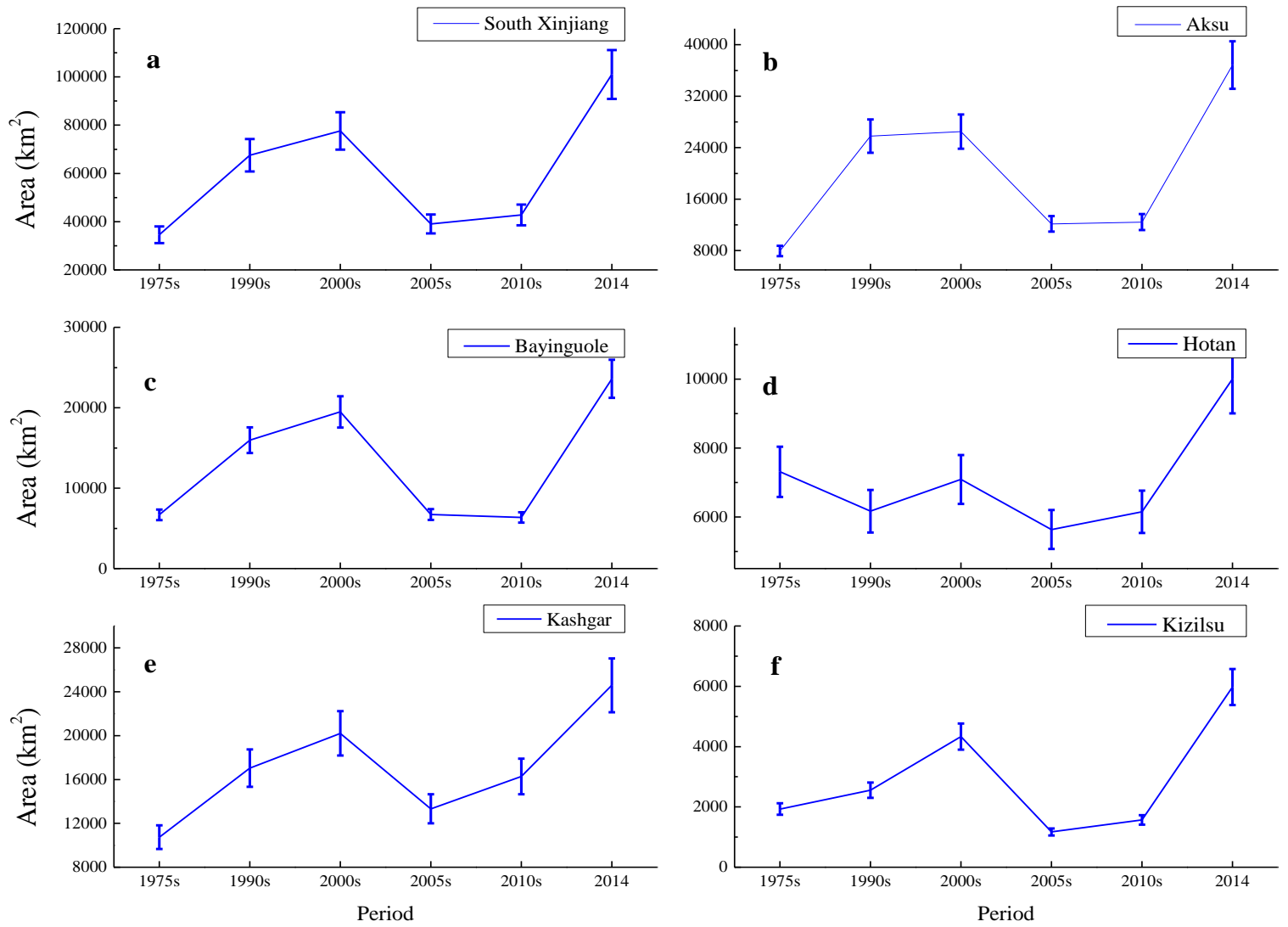

Figure 6. Temporal changes of oases area during past decades.

\subsection{Temporal changes of hydrometerological conditions}

Figure 7 indicates that precipitation and temperature have increased slightly during past four decades. Results derived from data sets collected from 39 weather stations and 29 hydrological stations indicate that precipitation, relative humidity, vapor pressure, and the aridity increased since 1986 and surface temperature began to increase in 1996. However, the time of sunshine started to decrease from 1990, and the potential evapotranspiration (ET) began to descend since 1985 due to the decreasing wind speed rather than the increasing temperature [30,35]. Because of the intensive evapotranspiration, the relatively less precipitation would contribute less to vegetation growth. The seasonal and phonological change of oasis vegetation are significantly dependent on the water allocation of river runoff. The streamflow in Aksu River, Yarkand River and Kaidu-Kongque River (near Korla) (Figure 1) shows an increasing trend, while the streamflow in Hotan River is of significant fluctuation (Figure 8a-d). The annual runoff in the mainstream of Tarim River has decreased significantly since 1950s over decadal timescale. The decrease in streamflow of the mainstream of the Tarim River results from anthropogenic activities (such as irrigation and domestic water use) and climatic changes [30,31] in the upper headwater areas and oases.

Although precipitation and the streamflow from the headwater of the Tarim River exhibited significant increase, decreasing trend has been detected in the streamflow along the mainstream of the river. This suggested that anthropogenic activities instead of the climate change dominated the streamflow cessation and the drying-up of the river [15,31]. 

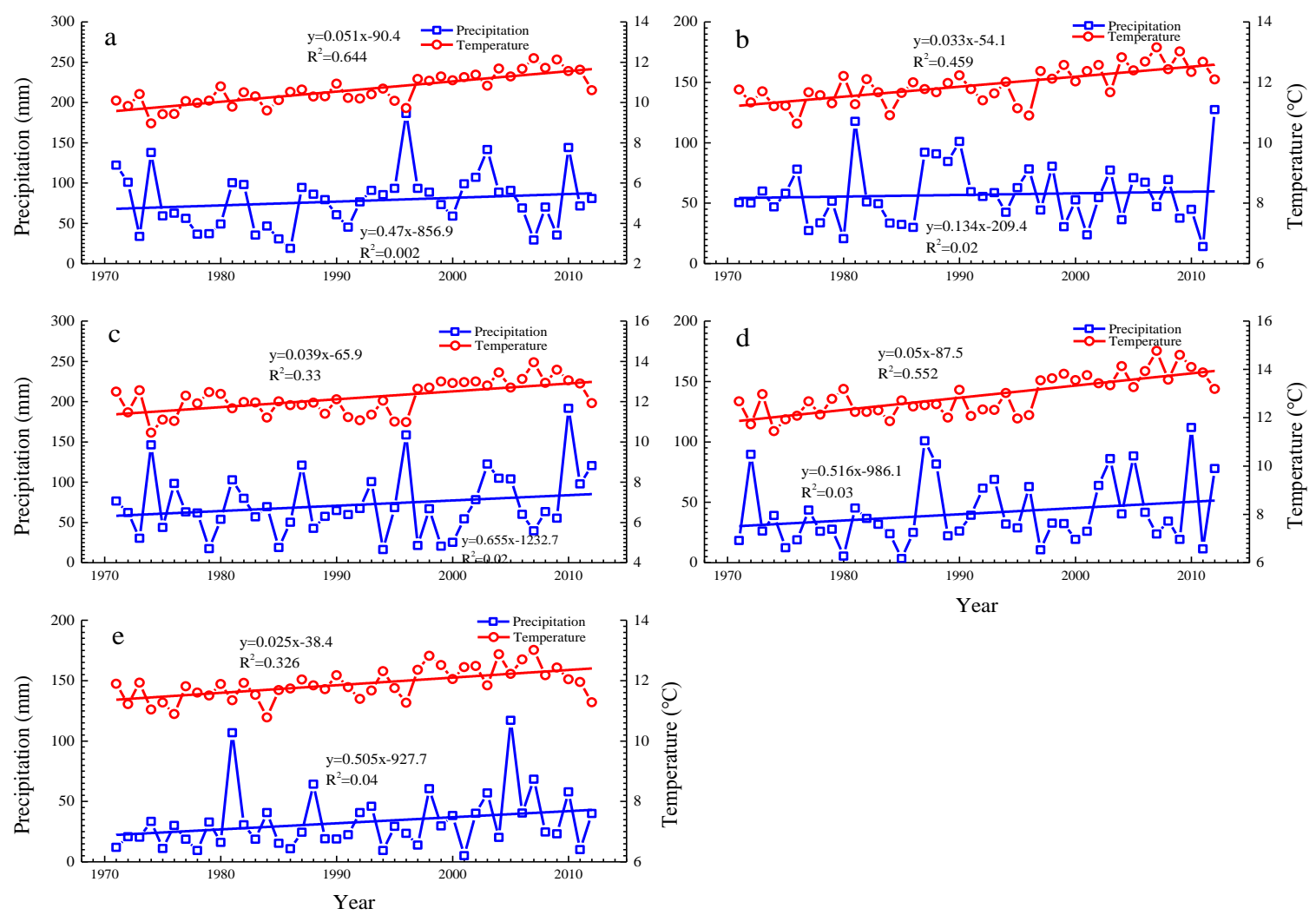

Figure 7. Temporal changes of precipitation and temperature in South Xinjiang. a. Aksu; b. Korla; c. Kashgar; d.

Hotan; e. Ruoqiang.
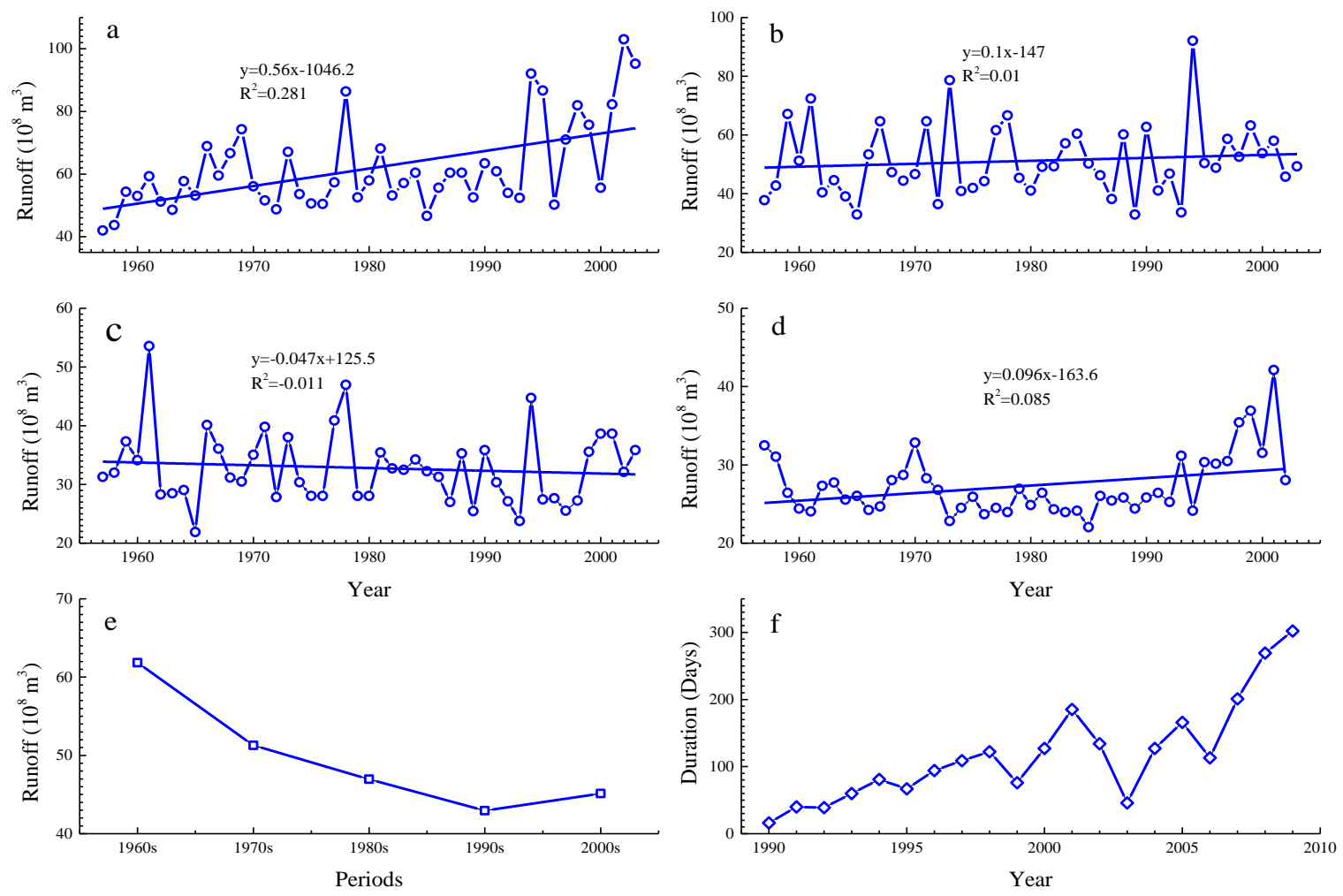

Figure 8. The temporal change of annual runoff between 1957-2010 in Aksu River, Yarkant River, Hotan River,

Kaidu-Kongque River and the mainstream of Tarim River. a. Aksu River; b. Yarkant River; C. Hotan River; d. Kaidu-Kongque River; e. Decades-average annual runoff in the mainstream of Tarim River during 1950s2000s; f. The dry-ups in the mainstream of the Tarim River. The data was retrieved from Chen et al. (2009),

Chen et al. (2011) and Tao et al. (2011). 


\subsection{Natural and anthropogenic controls on oases dynamics}

The investigations on hydrometerological changes have shown that there is an increasing trend in precipitation and decreasing trend in potential evapotranspiration $[35,36]$. This indicates that the more precipitation will be supplied to vegetation and will contribute to the survival of the arid fragile ecosystems, especially for those in the margin of oases and deserts.

Although effective precipitation for vegetation growth increased during past decades, the increasing water irrigations should primarily account for the oases expansion (Figures 7e and 8). The quantitative assessment indicates that local human activities since the 1970s led to a decrease of the water volume diverted into the main stream of the Tarim River Basin, which had been aggravated in the 2000s [30]. The water consumption exhibits a complicated spatial pattern between different reaches due to the difference water resource allocation strategy in the river basin [15]. The irrigated area in the Tarim River basin has increased obviously (Figure 10), particularly after 2000 with the growing population. The actual irrigated area for the "four headstreams (Aksu River, Yarkand River, Hotan River and Kaidu-Kongque River) and one mainstream" of the Tarim River largely exceeds the originally designed irrigated area [15]. If the specific irrigation volume in the Tarim River basin is 1.2 $\times 10^{4} \mathrm{~m}^{3} / \mathrm{ha} \mathrm{m}^{2}$, more about $5.0 \times 10^{6} \mathrm{~m}^{3}$ of water is required for the exceeding irrigated area [15], which need to be extracted from groundwater. Therefore, it can be inferred that the expansion of oases in South Xinjiang mainly resulted from the intensive water irrigations including both river water and underground water.

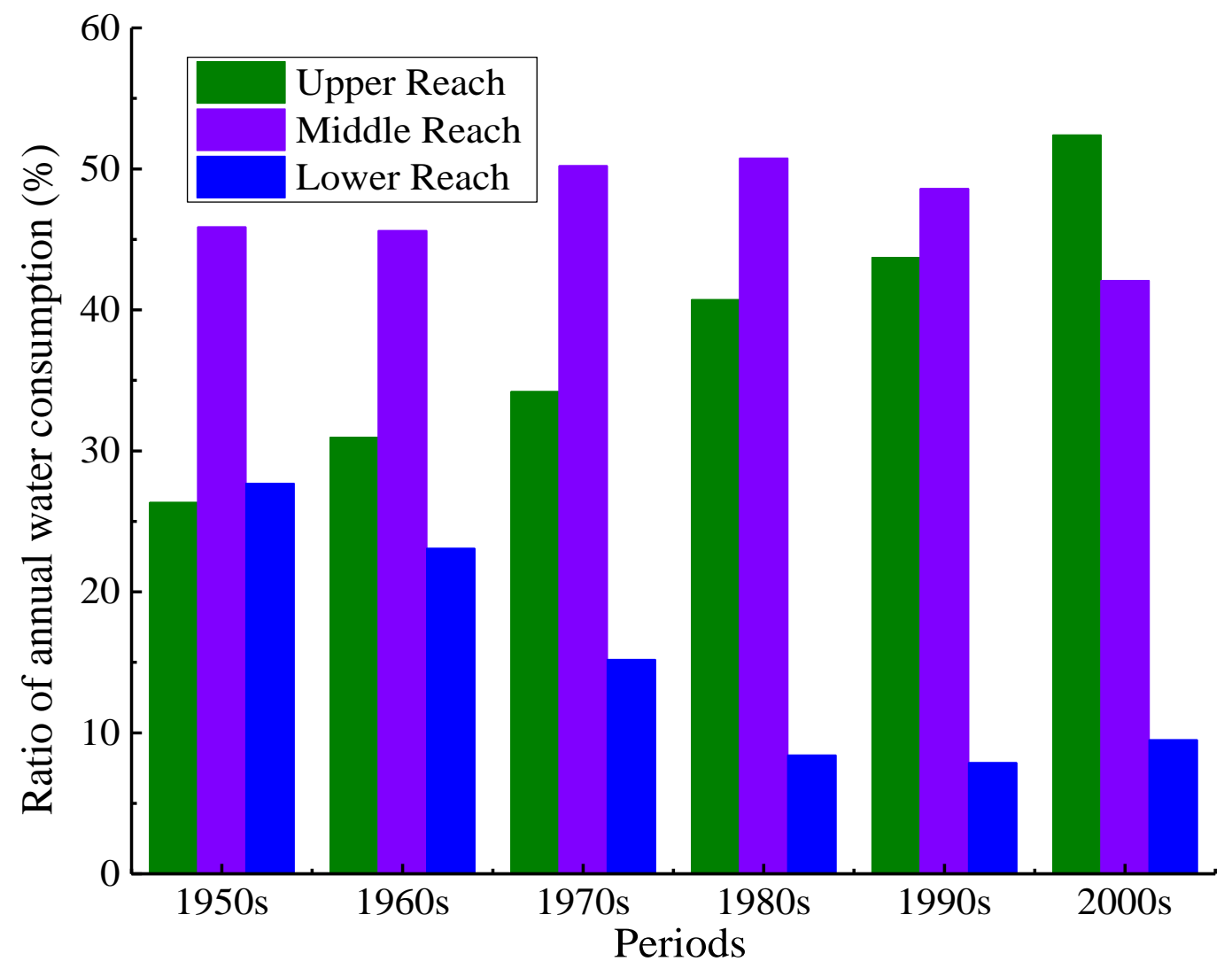

Fig. 9. Water consumption in the upper, middle and lower mainstream of the Tarim River (data retrieved from Chen et al. (2011)). 

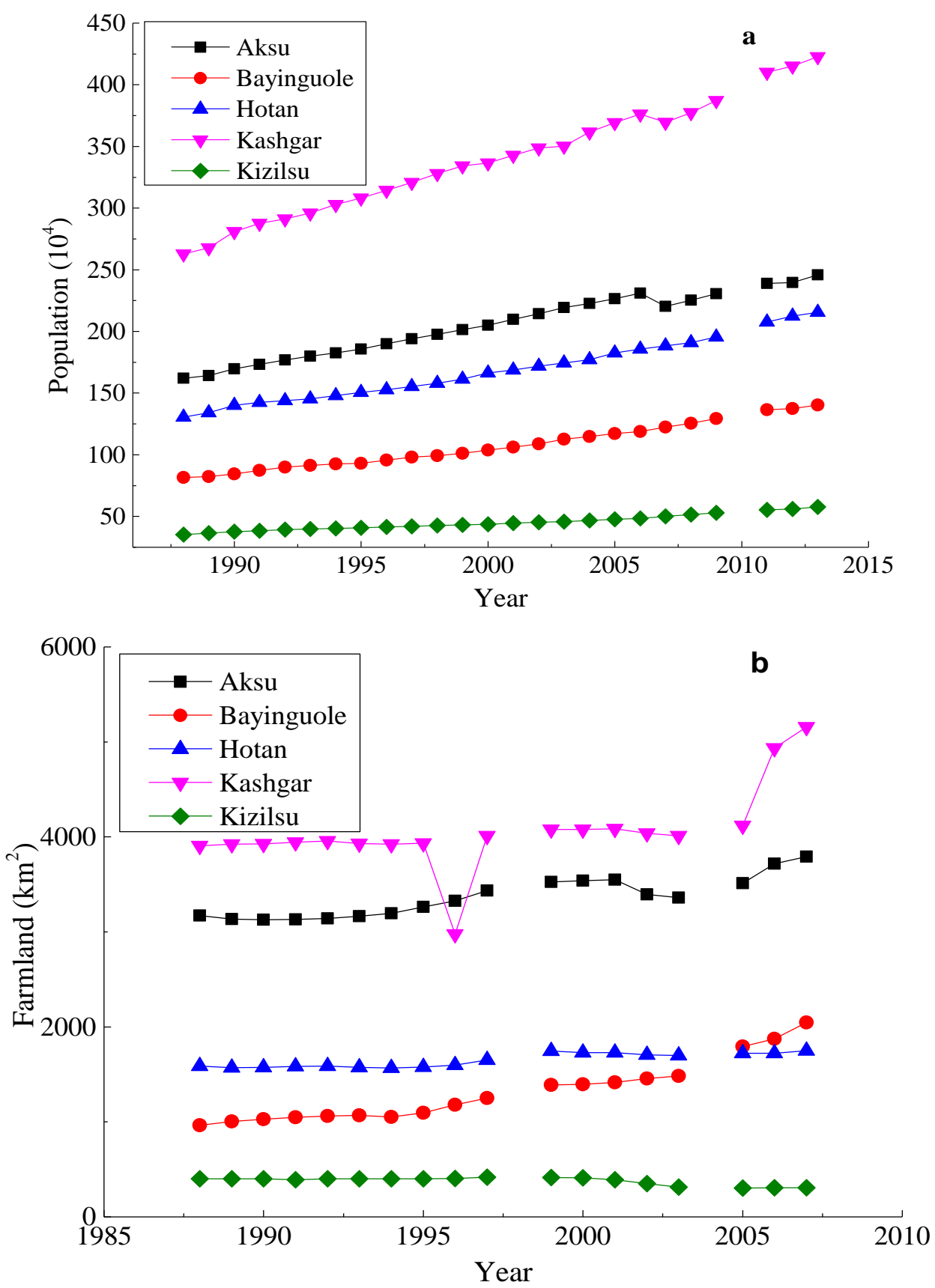

Fig. 10. Temporal changes of population and farmland area in South Xinjiang during 1988-2008.

a. Population change; b. Farmland change.

The increasing water irrigations could explain the total expansion of oases from 1975s-2014, although with a shrinkage between 2000s and 2010s (Figures 7 and 8). The shrinkage of oases between 2000s and 2010s may arise from the rapid urbanization and expansion of farmland (Figure 10b). The rapid growth of population and urbanization rate after 2000 (Figure 10a) probably led to the destruction of large-scale cropland and vegetated area. In the meantime, the land reclamation for crop planting may change the original ecosystems around the new cropland and resulted in large scale land degradation.

The spatial pattern of vegetation cover changes between 1990s and 2014s (Figures 3f and 4) could be explained by the spatial difference of water consumption and allocation along the Tarim River (Figure 9). The increasing streamflow in headwaters and decreasing streamflow in mainstream of Tarim River suggested an increasing water consumption in the upper reaches and headwaters, 
which to large extent account for the expansion of oases in the south part of South Xinjiang, despite of some sparse decrease. The relatively large-scale decrease in oases vegetation cover in Northern part of South Xinjiang (Bayinguole) maybe resulted from the reducing water supply in the middle and lower Tarim River (Figure 9). Following the frequent dry-ups in the middle and lower Tarim River (Figure 8f), water supply for irrigation and crop production reduced, resulting in land degradation and bare lands.

The multiple regression equation derived from the data of 18 sample counties are given as follow:

$$
A=0.148 R+0.089 T+0.064 P+0.496 L
$$

Here, $\mathrm{R}$ means rainfall or precipitation $(\mathrm{mm})$; $\mathrm{T}$ means temperature $\left({ }^{\circ} \mathrm{C}\right) ; \mathrm{P}$ means population (person); and $\mathrm{L}$ means arable land area $\left(\mathrm{km}^{2}\right)$. The relative contribution of each variables was derived by dividing their coefficient by the sum of all the coefficients [37]. The results show that annual precipitation, mean annual temperature, population, and farmland have $18.5 \%, 11.2 \%, 8 \%$, and $62.3 \%$ contribution to oases area change, respectively. Collectively, human activities contribute $70 \%$ of oases area change. Farmland reclamation and subsequent spatial change of water-heat flux primarily account for the oases expansion, which has more than $60 \%$ contribution. This suggests that the large scale water diversion and transformation for irrigation has to great extent change the water-heat flux and vegetation growth within the oasis $[15,30,31,36]$.

\section{Conclusions}

Dryland vegetation responds sensitively to climate change and human activities. The vegetation change has changed the ecological environment and exerted great pressure on social-economic development. Remote sensing provides a useful tool to monitor long-term vegetation dynamics, especially in drylands with less gauging data. In this study, the vegetation cover change of the Tarim Basin was using Landsat data set of six epochs, 1975s, 1990s, 2000s, 2005s, 2010s and 2014. The originally orthorectified datasets were converted from $\mathrm{DN}$ raw products to usable surface reflectance products through atmospheric correction. The NDVI maps were produced to show the spatiotemporal changes of oases. We have the following conclusions.

(1) The vegetation coverage of oases increased from $34600 \mathrm{~km}^{2}$ in $1975 \mathrm{~s}$ to $101000 \mathrm{~km}^{2}$ in 2014. However, vegetation coverage decreases from $77600 \mathrm{~km}^{2}$ in $2000 \mathrm{~s}$ to $42680 \mathrm{~km}^{2}$ in 2010s. At prefecture scale, the temporal changes of oases area in other four prefectures have the same increasingdecreasing-increasing changing trends with the whole study region except Hotan.

(2) The increasing precipitation and decreasing potential evapotranspiration would improve the vegetation growth and expansion of oases, particularly along the margin of the desert. However, large scale expansion of oases mainly resulted from increased water irrigations. The percentage of annul water irrigations increased from $26 \%$ in 1950 s to $52 \%$ in 2000 s in the upper Tarim River, and decreased from $27 \%$ in 1950 s to $9 \%$ in 2000 s in the lower Tarim River. The decrease of oases area from 2000s to 2010s probably resulted from the rapid urbanization and intensive land reclamation.

(3) The spatial pattern of vegetation cover changes between 1990s and 2014s could be explained by the spatial difference of water irrigations and allocation along the Tarim River. The increasing streamflow in headwaters and decreasing streamflow in mainstream of Tarim River suggested an increasing water consumption in the upper reaches and headwaters, which to large extent account for the expansion of oases in the south part of South Xinjiang. The large-scale local decrease in oases vegetation cover in Northern part of South Xinjiang (Aksu and Bayinguole) maybe resulted from the reducing water supply and intensive land reclamation in the middle and lower Tarim River. 
(4) The results of multiple regression show that human activities contribute $70 \%$ of oases area change. Farmland reclamation is the primary determinant for the oases expansion, which has more than $60 \%$ contribution. Human induced water resources reallocation and heat energy balance is the primary cause of total oasis change.

Supplementary Materials: Table S1: The World Reference System (WRS1; path and row) and acquisition date of the 1975s Landsat data collection; Table S1: The World Reference System (WRS2; path and row) and acquisition date of the epoch 1990s, 2000s, 2005s, 2010s and 2014 Landsat data collection.

Acknowledgments: This study was financially supported by "Western Light" program of Chinese Academy of Sciences (YBXM-2013-05), Xinjiang Uyghur autonomous region of China (XJGRI2014021), Director Fund Project of the Institute of Remote Sensing and Digital Earth of Chinese Academy of Sciences (Y5ZZ06101B), Xinjiang Uygur Autonomous Region Science Foundation (201442137-11). The datasets used in this study is provided by GLCF Program of Maryland University and International Scientific \& Technical Data Mirror Site, Computer Network Information Center, Chinese Academy of Sciences. Thanks are given to China Meteorological Data Center for permitting us to access the meteorological data. Jimin Sun from Institute of Geology and Geophysics of CAS are appreciated for his constructive suggestions.

Author Contributions: Y.M conceived and designed the experiments; A. M., F. Y., J. W and Y.M. performed the experiments; Y.M. analyzed the data; Y.M. wrote the paper.

\section{References}

1. Andela, N.; Liu, Y.Y.; van Dijk, A.I.J.M.; de Jeu, R.A.M.; McVicar, T.R. Global changes in dryland vegetation dynamics (1988-2008) assessed by satellite remote sensing: Comparing a new passive microwave vegetation density record with reflective greenness data. Biogeosciences 2013, 10, 6657-6676.

2. Wang, L.; D'Odorico, P.; Evans, J.P.; Eldridge, D.J.; McCabe, M.F.; Caylor, K.K.; King, E.G. Dryland ecohydrology and climate change: Critical issues and technical advances. Hydrol. Earth Syst. Sci. 2012, 16, 2585-2603.

3. Reynolds, J.F.; Smith, D.M.S.; Lambin, E.F.; Turner, B.L.; Mortimore, M.; Batterbury, S.P.J.; Downing, T.E.; Dowlatabadi, H.; Fernández, R.J.; Herrick, J.E., et al. Global desertification: Building a science for dryland development. Science 2007, 316, 847-851.

4. Grace, J.; José, J.S.; Meir, P.; Miranda, H.S.; Montes, R.A. Productivity and carbon fluxes of tropical savannas. Journal of Biogeography 2006, 33, 387-400.

5. Tietjen, B.; Jeltsch, F.; Zehe, E.; Classen, N.; Groengroeft, A.; Schiffers, K.; Oldeland, J. Effects of climate change on the coupled dynamics of water and vegetation in drylands. Ecohydrology 2010, 3, 226-237.

6. Bai, J.; Chen, X.; Li, L.; Luo, G.; Yu, Q. Quantifying the contributions of agricultural oasis expansion, management practices and climate change to net primary production and evapotranspiration in croplands in arid northwest china. Journal of Arid Environments 2014, 100-101, 31-41.

7. Xie, Y.C.; Gong, J.; Sun, P.; Gou, X.H. Oasis dynamics change and its influence on landscape pattern on jinta oasis in arid china from 1963a to 2010a: Integration of multi-source satellite images. International Journal of Applied Earth Observation and Geoinformation 2014, 33, 181-191.

8. Bourque, C.P.A.; Hassan, Q.K. Vegetation control in the long-term self-stabilization of the liangzhou oasis of the ppper shiyang river watershed of west-central gansu, northwest china. Earth Interactions 2009, 13, 1-22.

9. Yang, $\mathrm{X}$. The oases along the keriya river in the taklamakan desert, china, and their evolution since the end of the last glaciation. Environ Geol 2001, 41, 314-320. 
10. Luedeling, E.; Buerkert, A. Typology of oases in northern oman based on landsat and srtm imagery and geological survey data. Remote Sensing of Environment 2008, 112, 1181-1195.

11. Bourque, C.P.A.; Mir, M.A. Seasonal snow cover in the qilian mountains of northwest china: Its dependence on oasis seasonal evolution and lowland production of water vapour. J Hydrol 2012, 454-455, 141-151.

12. Ishiyama, T.; Saito, N.; Fujikawa, S.; Ohkawa, K.; Tanaka, S. Ground surface conditions of oases around the taklimakan desert. Advances in Space Research 2007, 39, 46-51.

13. Chu, P.C.; Lu, S.; Chen, Y. A numerical modeling study on desert oasis self-supporting mechanisms. J Hydrol 2005, 312, 256-276.

14. Gao, Y.; Chen, Y.; Lü, S. Numerical simulation of the critical scale of oasis maintenance and development in the arid regions of northwest china. Adv Atmos Sci 2004, 21, 113-124.

15. Chen, Y.; Ye, Z.; Shen, Y. Desiccation of the tarim river, xinjiang, china, and mitigation strategy. Quaternary International 2011, 244, 264-271.

16. Liu, Y.Y.; van Dijk, A.I.J.M.; McCabe, M.F.; Evans, J.P.; de Jeu, R.A.M. Global vegetation biomass change (1988-2008) and attribution to environmental and human drivers. Global Ecology and Biogeography 2013, 22, 692-705.

17. Feng, M.; Sexton, J.O.; Huang, C.; Masek, J.G.; Vermote, E.F.; Gao, F.; Narasimhan, R.; Channan, S.; Wolfe, R.E.; Townshend, J.R. Global surface reflectance products from landsat: Assessment using coincident modis observations. Remote Sensing of Environment 2013, 134, 276-293.

18. Tucker, C.J. Red and photographic infrared linear combinations for monitoring vegetation. Remote Sensing of Environment 1979, 8, 127-150.

19. Tucker, C.J.; Vanpraet, C.L.; Sharman, M.J.; Van Ittersum, G. Satellite remote sensing of total herbaceous biomass production in the senegalese sahel: 1980-1984. Remote Sensing of Environment 1985, 17, 233-249.

20. Zhang, H.; Wu, J.W.; Zheng, Q.H.; Yu, Y.J. A preliminary study of oasis evolution in the tarim basin, xinjiang, china. Journal of Arid Environments 2003, 55, 545-553.

21. Wang, T.; Yan, C.Z.; Song, X.; Xie, J.L. Monitoring recent trends in the area of aeolian desertified land using landsat images in china's xinjiang region. ISPRS Journal of Photogrammetry and Remote Sensing 2012, 68, 184-190.

22. Jia, B.; Zhang, Z.; Ci, L.; Ren, Y.; Pan, B.; Zhang, Z. Oasis land-use dynamics and its influence on the oasis environment in xinjiang, china. Journal of Arid Environments 2004, 56, 11-26.

23. Yang, X.; Liu, Z.; Mang, F.; White, P.D.; Wang, X. Hydrological changes and land degradation in the southern and eastern tarim basin, xinjiang, china. Land Degrad Dev 2006, 17, 381-392.

24. Zhang, X.; Wang, X.; Yan, P. Re-evaluating the impacts of human activity and environmental change on desertification in the minqin oasis, china. Environ Geol 2008, 55, 705-715.

25. Ji, X.; Kang, E.; Chen, R.; Zhao, W.; Zhang, Z.; Jin, B. The impact of the development of water resources on environment in arid inland river basins of hexi region, northwestern china. Environ Geol 2006, 50, 793-801.

26. Chen, Y.; Xu, C.; Hao, X.; Li, W.; Chen, Y.; Zhu, C.; Ye, Z. Fifty-year climate change and its effect on annual runoff in the tarim river basin, china. Quaternary International 2009, 208, 5361.

27. Chen, Y.N.; Li, W.H.; Xu, C.C.; Hao, X.M. Effects of climate change on water resources in tarim river basin, northwest china. Journal of Environmental Sciences 2007, 19, 488-493. 
28. Chen, Y.; Cui, W.; Li, W.; Chen, Y.; Zhang, H. Utilization of water resources and ecological protection in the tarim river. Acta Geographica Sinica 2003, 58, 215-217.

29. Hao, X.M.; Chen, Y.N.; Li, W.H. Impact of anthropogenic activities on the hydrologic characters of the mainstream of the tarim river in xinjiang during the past 50 years. Environ Geol 2009, 57, 435-445.

30. Tao, H.; Gemmer, M.; Bai, Y.; Su, B.; Mao, W. Trends of streamflow in the tarim river basin during the past 50 years: Human impact or climate change? J Hydrol 2011, 400, 1-9.

31. Xu, Z.X.; Chen, Y.N.; Li, J.Y. Impact of climate change on water resources in the tarim river basin. Water Resources Management 2004, 18, 439-458.

32. Xu, C.; Chen, Y.; Chen, Y.; Zhao, R.; Ding, H. Responses of surface runoff to climate change and human activities in the arid region of central asia: A case study in the tarim river basin, china. Environmental Management 2013, 51, 926-938.

33. Xiao, J.; Moody, A. A comparison of methods for estimating fractional green vegetation cover within a desert-to-upland transition zone in central new mexico, USA. Remote Sensing of Environment 2005, 98, 237-250.

34. Zhou, L.; Tucker, C.J.; Kaufmann, R.K.; Slayback, D.; Shabanov, N.V.; Myneni, R.B. Variations in northern vegetation activity inferred from satellite data of vegetation index during 1981 to 1999. Journal of Geophysical Research 2001, 106, 20069-20083.

35. Zheng, C.; Wang, Q. Spatiotemporal variations of reference evapotranspiration in recent five decades in the arid land of northwestern china. Hydrological Processes 2014, 28, 6124-6134.

36. Tao, H.; Gemmer, M.; Song, Y.; Jiang, T. Ecohydrological responses on water diversion in the lower reaches of the tarim river, china. Water Resources Research 2008, 44, W08422.

37. Xu, J.X. Sediment flux to the sea as influenced by changing human activities and precipitation: Example of the yellow river, china. Environmental Management 2003, 31, 03280341. 